\title{
Progressive Taxation as an Automatic Destabilizer under Endogenous Growth*
}

\author{
Shu-Hua Chen ${ }^{\dagger}$ \\ National Taipei University
}

\author{
Jang-Ting Guo \\ University of California, Riverside
}

July 27, 2015

\begin{abstract}
It has been shown that in an otherwise standard one-sector real business cycle model with an indeterminate steady state under laissez faire, sufficiently progressive income taxation may stabilize the economy against aggregate fluctuations caused by agents' animal spirits. We show that this previous finding can be overturned within an identical model which allows for sustained endogenous growth. Specifically, progressive taxation may operate like an automatic destabilizer that leads to equilibrium indeterminacy and sunspotdriven cyclical fluctuations in an endogenously growing macroeconomy. This instability result is obtained under two tractable progressive tax policy formulations that have been considered in the existing literature.
\end{abstract}

Keywords: Progressive Income Taxation, Automatic Stabilizer, Equilibrium Indeterminacy, Endogenous Growth.

JEL Classification: E62, O41.

\footnotetext{
${ }^{*}$ We thank Juin-Jen Chang, Been-Lon Chen, Hung-Ju Chen, Shin-ichi Fukuda, Ching-Chong Lai, Yiting Li, David Malueg, Kazuo Mino, Victor Ortego-Marti, Cheng Wang, Yan Zhang, and seminar participants at Shanghai University of Economics and Finance, Fudan University, National Tsing Hua University, National Taiwan University, Academia Sinica, Society for the Advancement of Economic Theory Conference, Asian Meeting of the Econometric Society, Annual Conference on Computing in Economics and Finance, and Annual Conference of the Asia-Pacific Economic Association for helpful comments and suggestions. Part of this research was conducted while Guo was a visiting research fellow of economics at Academia Sinica, Taipei, Taiwan, whose hospitality is greatly appreciated. Of course, all remaining errors are our own.

${ }^{\dagger}$ Department of Economics, National Taipei University, 151 University Rd., San Shia, Taipei, 237 Taiwan, Phone: 886-2-8674-7168, Fax: 886-2-2673-9727, E-mail: shchen@mail.ntpu.edu.tw.

${ }^{\ddagger}$ Corresponding Author. Department of Economics, 3133 Sproul Hall, University of California, Riverside, CA 92521, USA, Phone: 1-951-827-1588, Fax: 1-951-827-5685, E-mail: guojt@ucr.edu.
} 


\section{Introduction}

As in traditional Keynesian macroeconomics, the conventional view on progressive taxation states that it automatically acts to alleviate the magnitude of fluctuations in households' disposable income and consumption expenditures. It follows that the cyclical volatilities of output and employment are ceteris paribus smaller when the economy is subject to a more progressive income tax schedule. As it turns out, this result continues to hold in the context of Benhabib and Farmer's (1994) one-sector real business cycle (RBC) model with aggregate increasing returns-to-scale in production, which in turn leads to an indeterminate steady state under laissez faire and no persistent growth. In particular, Guo and Lansing (1998) and Dromel and Pintus (2007) find that a sufficiently strong tax progressivity is able to stabilize the BenhabibFarmer economy against business cycles driven by agents' animal spirits or sunspots. ${ }^{1}$ Perhaps quite surprisingly, we show that these authors' findings are not robust within an identical model which allows for sustained endogenous growth, ${ }^{2}$ i.e. progressive income taxation may operate like an automatic destabilizer that generates equilibrium indeterminacy and belief-driven fluctuations in several parametric configurations of our endogenously growing macroeconomy.

Our analysis starts with incorporating Guo and Lansing's (1998) nonlinear fiscal policy rule, which displays continuously increasing average and marginal tax rates, into the endogenous-growth version of Benhabib and Farmer's (1994, section 5) one-sector representative agent model in continuous time. ${ }^{3}$ To facilitate comparison with previous work, government spending is postulated to be useless that does not contribute to utility or production. ${ }^{4}$ We focus on local dynamics of the economy's interior balanced growth path(s) along which hours worked are stationary, and output, consumption and physical capital all grow at a common

\footnotetext{
${ }^{1}$ In a similar vein, Schmitt-Grohé and Uribe (1997) show that equilibrium indeterminacy can arise within standard one-sector RBC models under constant returns-to-scale in production and a balanced-budget rule where fixed government spending is financed by proportional taxation on labor or total income. This fiscal formulation is qualitatively equivalent to regressive income taxation that may destabilize the no-growth macroeconomy.

${ }^{2}$ It is straightforward to show that as in the no-growth counterpart, progressive income taxation may work like an automatic stabilizer in the exogenous-growth version of Banhabib and Farmer's (1994) model.

${ }^{3}$ In our previous study, Chen and Guo (2015) show that the Guo-Lansing progressive tax schedule will destabilize a one-sector $A K$ model of endogenous growth with fixed hours worked. By contrast, the present paper finds that variable labor supply plays an important role in affecting the economy's equilibrium dynamics.

${ }^{4}$ There has been an extensive literature that explores the macroeconomic effects of various tax policies in an endogenous growth setting with useful public expenditures that contribute to firms' productivity and/or households' utility. See, for example, Barro (1990), Barro and Sala-i-Martin (1992), Futagami, Mortia and Shibata (1993), Glomm and Ravikumar (1994, 1997), Cazzavillan (1996), Turnovsky (1997, 1999), Zhang (2000), Baier and Glomm (2001), Yamarik (2001), Palivos and Zhang (2002), Park and Philippopoulos (2002), Li and Sarte (2004), Chen (2006), Greiner (2006, 2007), Slobodyan (2006), Hu, Ohdoi and Shimomura (2008), and Chen and Guo (2013), among others.
} 
constant rate. The resulting interrelations between fiscal progressivity and macroeconomic (in)stability from three variants of our model are summarized as follows.

First, when the degree of productive externalities from labor hours is sufficiently low (including zero), the economy's unique balanced growth path (BGP) is shown to exhibit equilibrium indeterminacy and endogenous growth fluctuations under progressive income taxation; whereas Benhabib and Farmer (1994) find that the same parameterization yields local determinacy and saddle path stability without government intervention. In this case, the traditional viewpoint about progressive taxation is overturned. To understand the intuition for this indeterminacy result, start from a particular balanced-growth equilibrium, and suppose that agents become optimistic about the future of the economy. Acting upon this expectation, the representative household will reduce consumption and raise investment today, hence another dynamic trajectory ensues. When the tax progressivity is positive, we analytically show that the after-tax return on investment is monotonically increasing along the positively-sloped transitional path as the consumption-to-capital ratio rises. As a result, agents' initial rosy anticipations are validated and the alternative path becomes a self-fulfilling equilibrium.

Second, two possibilities for the specification in which our model possesses dual BGP equilibria are analyzed. When the tax progressivity exceeds a critical level such that the after-tax equilibrium wage-hours locus is flatter than the labor supply curve, we show that both balanced growth paths are locally indeterminate, indicating that progressive income taxation may work as an automatic destabilizer. This result turns out to be exactly opposite to that obtained in Guo and Lansing (1998) whereby the same fiscal-progressivity threshold is needed to stabilize the no-sustained-growth version of Benhabib and Farmer's (1994) economy against sunspot-driven aggregate fluctuations. When the after-tax equilibrium wagehours locus is upward-sloping and steeper than the labor supply curve, the requisite condition that governs the local stability properties for this formulation cannot be analytically derived. Therefore, numerical experiments are conducted to quantitatively explore the model's equilibrium dynamics. Under the parameterization that is commonly adopted in the RBC-based indeterminacy literature, we find that the high-growth BGP is an indeterminate sink, and that the low-growth BGP exhibits saddle-path stability and equilibrium uniqueness. In this case, progressive taxation does not affect macroeconomic (in)stability as the two interior balancedgrowth equilibria in the original Benhabib-Farmer model without government intervention display identical equilibrium dynamics. For our third configuration with zero tax progressivity or flat income taxation, its local stability properties also remain qualitatively unchanged 
vis-à-vis those within Benhabib and Farmer's (1994) laissez-faire endogenous growth model, regardless of whether there exists one or two balanced growth paths in the macroeconomy.

Next, we examine the (de)stabilization effects of Dromel and Pintus's (2007) linearly progressive tax scheme which imposes a constant marginal tax rate on the representative household's taxable income when it is higher than an exemption level. Although the condition that determines the number of BGP's in this setting is the same as that under Guo and Lansing's (1998) fiscal policy rule, the resulting local dynamics are different. Specifically, as in Benhabib and Farmer's (1994) no-government counterpart, our model's unique balanced growth path under linearly progressive taxation continues to display saddle path stability without the possibility of belief-driven cyclical fluctuations. On the other hand, the economy may possess two balanced-growth equilibria when the productive degree of labor externalities is sufficiently high. In this case, we find that both BGP's exhibit equilibrium indeterminacy and belief-driven growth fluctuations. This in turn implies that linearly progressive taxation can operate like an automatic destabilizer in our endogenously growing macroeconomy as well.

The remainder of this paper is organized as follows. Section 2 describes the model and analyzes its equilibrium conditions under a fiscal policy rule that exhibits continuously increasing average and marginal tax rates. Section 3 investigates the local stability properties associated with the economy's balanced growth path(s). Section 4 analytically examines the interrelations between linearly progressive taxation and equilibrium (in)determinacy within our endogenously growing macroeconomy. Section 5 concludes.

\section{The Economy}

Our analysis begins with incorporating a progressive fiscal policy rule a la Guo and Lansing (1998), which exhibits continuously increasing average and marginal tax rates, into the endogenous-growth version of Benhabib and Farmer's (1994, section 5) one-sector representative agent macroeconomy in continuous time. Households live forever, and derive utility from consumption and leisure. The production side consists of a social technology that displays increasing returns-to-scale due to positive productive externalities from aggregate capital and labor inputs. The government balances the budget each period by spending its tax revenue on goods and services that do not contribute to the households' utility or the firms' production. We assume that there are no fundamental uncertainties present in the economy. 


\subsection{Firms}

There is a continuum of identical competitive firms, with the total number normalized to one. The representative firm $i$ produces output $y_{i t}$ according to a Cobb-Douglas production function

$$
y_{i t}=x_{t} k_{i t}^{\alpha} h_{i t}^{1-\alpha}, \quad 0<\alpha<1,
$$

where $k_{i t}$ and $h_{i t}$ are capital and labor inputs, respectively, and $x_{t}$ represents positive productive externalities that are taken as given by each individual firm. As in Benhabib and Farmer (1994), we postulate that externalities take the form

$$
x_{t}=k_{t}^{1-\alpha} h_{t}^{(1-\alpha) \chi}, \quad \chi \geq 0
$$

where $k_{t}$ and $h_{t}$ denote the economy-wide levels of capital and labor services. In a symmetric equilibrium, all firms make the same decisions such that $k_{i t}=k_{t}$ and $h_{i t}=h_{t}$, for all $i$ and $t$. As a result, (2) can be substituted into (1) to obtain the following aggregate increasing returns-to-scale production function for total output $y_{t}$ :

$$
y_{t}=k_{t} h_{t}^{(1-\alpha)(1+\chi)}
$$

Notice that the economy exhibits sustained economic growth because the social technology (3) displays linearity in physical capital. Under the assumption that factor markets are perfectly competitive, the first-order conditions for the representative firm's profit maximization problem are given by

$$
\begin{gathered}
r_{t}=\alpha \frac{y_{t}}{k_{t}}, \\
w_{t}=(1-\alpha) \frac{y_{t}}{h_{t}},
\end{gathered}
$$

where $r_{t}$ is the capital rental rate and $w_{t}$ is the real wage rate.

\subsection{Households}

The economy is also populated by a unit measure of identical infinitely-lived households, each of which maximizes a discounted stream of utilities over its lifetime 


$$
\int_{0}^{\infty}\left\{\log c_{t}-A \frac{h_{t}^{1+\gamma}}{1+\gamma}\right\} e^{-\rho t} d t, \quad A>0,
$$

where $c_{t}$ is consumption, $\gamma \geq 0$ denotes the inverse of the intertemporal elasticity of substitution in labor supply, and $\rho>0$ is the subjective rate of time preference. The budget constraint faced by the representative household is

$$
c_{t}+i_{t}=\left(1-\tau_{t}\right)\left(r_{t} k_{t}+w_{t} h_{t}\right)
$$

where $i_{t}$ is gross investment, and $\tau_{t}$ represents a proportional income tax rate. Investment adds to the stock of physical capital according to the following law of motion:

$$
\dot{k}_{t}=i_{t}-\delta k_{t}, \quad k_{0}>0 \text { given, }
$$

where $\delta \in(0,1)$ is the capital depreciation rate.

In terms of the income tax rate, we adopt the sustained-growth version of Guo and Lansing's (1998, p.485, footnote 4) nonlinear tax formulation and postulate $\tau_{t}$ as

$$
\tau_{t}=1-\eta\left(\frac{y_{t}^{*}}{y_{t}}\right)^{\phi}, \eta \in(0,1), \phi \in[0,1),
$$

where $y_{t}\left(=r_{t} k_{t}+w_{t} h_{t}\right)$ is the household's taxable income, and $y_{t}^{*}$ denotes a benchmark level of income that is taken as given by the representative agent. In our model with ongoing growth, $y_{t}^{*}$ is set equal to the level of per capita output on the economy's balanced growth path (BGP) whereby $\frac{\dot{y}_{t}^{*}}{y_{t}^{*}}=\theta$ for all $t .{ }^{5}$ The parameters $\eta$ and $\phi$ govern the level and slope of the tax schedule, respectively. When $\phi>(<) 0$, the tax rate $\tau_{t}$ is monotonically increasing (decreasing) with the household's income $y_{t}$, i.e. agents with income above $y_{t}^{*}$ face a higher (lower) tax rate than those with income below $y_{t}^{*}$. When $\phi=0$, all households face the constant tax rate $1-\eta$ regardless of the level of their taxable income.

With regard to the progressivity features of the above tax structure, we note that the marginal tax rate $\tau_{m t}$, defined as the change in taxes paid by the household divided by the change in its taxable income, is given by

$$
\tau_{m t}=\frac{\partial\left(\tau_{t} y_{t}\right)}{\partial y_{t}}=\tau_{t}+\eta \phi\left(\frac{y_{t}^{*}}{y_{t}}\right)^{\phi}
$$

\footnotetext{
${ }^{5}$ In order for a balanced-growth equilibrium to exist in our model economy, the household's taxable income $y_{t}$ needs to grow at the same rate as the baseline level of output $y_{t}^{*}$. The constant growth rate $\theta$ for $y_{t}^{*}$ will be endogenously determined through the model's equilibrium conditions (see equation 21).
} 
Our analyses in this paper are restricted to the environment in which the government does not have access to lump-sum taxes or transfers, hence $\tau_{t}>0$ and $\tau_{m t}>0$ are imposed. We also require $\tau_{t}<1$ to ensure that the government can not confiscate all productive resources, and $\tau_{m t}<1$ so that households have an incentive to provide labor and capital services to firms. Along the economy's balanced-growth equilibrium path with $y_{t}=y_{t}^{*}$, these considerations imply that $\eta \in(0,1)$ and $\frac{\eta-1}{\eta}<\phi<1$, where $\frac{\eta-1}{\eta}<0$. Next, in order to satisfy the secondorder conditions for the representative household's dynamic optimization problem, its budget constraint (7) needs to be jointly concave in the state and control variables, i.e. $k_{t}, c_{t}$ and $h_{t}$. It turns out that this requirement, together with $0<\eta<1$ and $\phi<1$, yields a more restrictive lower bound on the tax-slope parameter $\phi \geq 0$. Given these restrictions on $\eta$ and $\phi$, it is straightforward to show that when $\phi>0$, the marginal tax rate (10) is higher than the average tax rate given by (9). In this case, the tax schedule is said to be "progressive". When $\phi=0$, the average and marginal tax rates coincide at the level of $1-\eta$, thus the tax schedule is "flat". Notice that the the original Benhabib-Farmer economy without income taxation corresponds to our model under $\eta=1$ and $\phi=0$.

As in Guo and Lansing (1998), we postulate that agents take into account the way in which the tax schedule affects their net earnings when they decide how much to work, consume and invest over their lifetimes. Consequently, it is the marginal tax rate of income $\tau_{m t}$ that governs the household's economic decisions. The first-order conditions for the representative household with respect to the indicated variables and the associated transversality condition (TVC) are

$$
\begin{aligned}
c_{t}: & \frac{1}{c_{t}}=\lambda_{t}, \\
h_{t}: & \frac{A h_{t}^{\gamma}}{\lambda_{t}}=\underbrace{\eta(1-\phi)\left(\frac{y_{t}^{*}}{y_{t}}\right)^{\phi}}_{\left(1-\tau_{m t}\right)} \underbrace{(1-\alpha) \frac{y_{t}}{h_{t}}}_{w_{t}}, \\
k_{t}: & \lambda_{t}[\underbrace{\eta(1-\phi)\left(\frac{y_{t}^{*}}{y_{t}}\right)^{\phi}}_{\left(1-\tau_{m t}\right)} \underbrace{\alpha \frac{y_{t}}{k_{t}}}_{r_{t}}-\delta]=\rho \lambda_{t}-\dot{\lambda}_{t}, \\
\mathrm{TVC}: & \lim _{t \rightarrow \infty} e^{-\rho t} \lambda_{t} k_{t}=0,
\end{aligned}
$$

where $\lambda_{t}>0$ is the the Lagrange multiplier on the budget constraint (7), (12) equates the slope of the household's indifference curve to the after-tax real wage, (13) is the consumption Euler 
equation, and (14) is the transversality condition. Notice that under the restrictions on $\eta$ and $\phi$ specified above, equations (11)-(13) are not only necessary, but also sufficient conditions for the unique global maximum of the household's optimization problem.

\subsection{Government}

The government sets the tax rate $\tau_{t}$ according to (9), and balances its budget each period. Hence, its instantaneous budget constraint is given by

$$
g_{t}=\tau_{t} y_{t}
$$

where $g_{t}$ is public spending on goods and services. With the government, the aggregate resource constraint for the economy is

$$
c_{t}+\dot{k}_{t}+\delta k_{t}+g_{t}=y_{t}
$$

\subsection{Balanced Growth Path}

We focus on the economy's balanced growth path(s) along which labor hours are stationary; whereas output, consumption, and physical capital all grow at a common constant rate $\theta$. To facilitate the subsequent dynamic analyses, we adopt the variable transformation $z_{t} \equiv \frac{c_{t}}{k_{t}}$. Our model's equilibrium conditions (with $\frac{\dot{y}_{t}^{*}}{y_{t}^{*}}=\theta$ imposed) can then be collapsed into the following autonomous dynamical system:

$$
\begin{aligned}
& \frac{\dot{h}_{t}}{h_{t}}=\frac{\left(1-\phi-A h_{t}^{1+\gamma}\right) z_{t}-\phi(\theta+\delta)-\rho}{(1-\phi)(1-\alpha)(1+\chi)-1-\gamma}, \\
& \frac{\dot{z}_{t}}{z_{t}}=\left\{1+\frac{A[(1-\phi) \alpha-1] h_{t}^{1+\gamma}}{(1-\phi)(1-\alpha)}\right\} z_{t}-\rho .
\end{aligned}
$$

An interior balanced-growth equilibrium is characterized by a pair of positive real numbers $\left(h^{*}, z^{*}\right)$ which satisfy $\dot{h}_{t}=\dot{z}_{t}=0$. It is straightforward to derive from (17) and (18) that $z^{*}$ is the solution(s) to the following nonlinear equation:

$$
z^{*}=\rho+\eta[1-\alpha(1-\phi)]\left[\frac{A z^{*}}{\eta(1-\phi)(1-\alpha)}\right]^{\frac{(1-\alpha)(1+\chi)}{(1-\alpha)(1+\chi)-1-\gamma}} \equiv f\left(z^{*}\right),
$$

and that the corresponding expressions for employment $h^{*}$ together with the common rate of economic growth $\theta$ are 


$$
h^{*}=\left[\frac{A z^{*}}{\eta(1-\phi)(1-\alpha)}\right]^{\frac{1}{(1-\alpha)(1+\chi)-1-\gamma}},
$$

and

$$
\theta=\frac{\alpha(1-\phi) z^{*}-\rho}{1-\alpha(1-\phi)}-\delta
$$

For the existence and number of the economy's interior balanced growth path(s), we use the right-hand side of (19) to obtain

$f^{\prime}\left(z^{*}\right)=\frac{\eta(1-\alpha)(1+\chi)[1-\alpha(1-\phi)]}{[(1-\alpha)(1+\chi)-1-\gamma] z^{*}}\left[\frac{A z^{*}}{\eta(1-\phi)(1-\alpha)}\right]^{\frac{(1-\alpha)(1+\chi)}{(1-\alpha)(1+\chi)-1-\gamma}} \lessgtr 0$ when $(1-\alpha)(1+\chi)-1-\gamma \lessgtr 0$,

and

$$
f^{\prime \prime}\left(z^{*}\right)=\frac{(1+\gamma) f^{\prime}\left(z^{*}\right)}{[(1-\alpha)(1+\chi)-1-\gamma] z^{*}}>0
$$

regardless of whether $f^{\prime}\left(z^{*}\right)$ is positive or negative. Therefore, the equilibrium $z^{*}$ can be located from the (possibly more than one) intersection(s) of $f\left(z^{*}\right)$ and the 45-degree line in the positive quadrant. Section 3 below will show that the number of BGP's in our model is governed by the sign of $f^{\prime}\left(z^{*}\right)$ or $(1-\alpha)(1+\chi)-1-\gamma$, which turns out to be identical to that in Benhabib and Farmer's (1994) macroeconomy under laissez faire.

\section{Macroeconomic (In)stability}

In terms of the local stability properties of a balanced-growth equilibrium path, we analytically compute the Jacobian matrix $J$ of the dynamical system, defined by (17) and (18), evaluated at $\left(h^{*}, z^{*}\right)$. The determinant and trace of the Jacobian are

$$
\begin{aligned}
\text { Det } & =\frac{\alpha \phi(1-\phi)(1+\gamma)\left(z^{*}-\rho\right) z^{*}}{[1-\alpha(1-\phi)][(1-\phi)(1-\alpha)(1+\chi)-1-\gamma]}, \\
\operatorname{Tr} & =\rho-\frac{(1-\phi)(1-\alpha)(1+\gamma)\left(z^{*}-\rho\right)}{[1-\alpha(1-\phi)][(1-\phi)(1-\alpha)(1+\chi)-1-\gamma]} .
\end{aligned}
$$

The equilibrium dynamics of our model's balanced growth path(s) are determined by comparing the eigenvalues of $J$ that have negative real parts to the number of initial conditions in the dynamical system (17)-(18), which is zero because $h_{t}$ and $z_{t}$ both are non-predeterminded 
jump variables. ${ }^{6}$ As a result, the BGP displays saddle-path stability and equilibrium uniqueness when both eigenvalues have positive real parts. If one or two eigenvalues have negative real parts, then the balanced-growth equilibrium path is locally indeterminate (i.e. a sink) and can be exploited to generate endogenous growth fluctuations driven by agents' self-fulfilling expectations or sunspots.

In the reminder of this section, we examine the existence and number of the economy's interior balanced-growth equilibrium path(s), as well as their associated local dynamics, in three parametric configurations.

\subsection{When $0<\phi<1$ and $(1-\alpha)(1+\chi)-1-\gamma<0$}

In this case, the fiscal policy rule (9) is progressive with $\phi \in(0,1)$, and the degree of productive externalities from labor hours in firms' production can be zero $(\chi=0)$. Based on $(22)$ and (23), Figure 1 depicts that $f\left(z^{*}\right)$ is a downward-sloping and convex curve which intersects the 45-degree line once in the positive quadrant; hence there exists a unique balanced-growth equilibrium characterized by $z^{*}$. Regarding local dynamics, it is straightforward to show that the determinant (24) of the model's Jacobian matrix $J$ is negative, indicating that the BGP exhibits equilibrium indeterminacy and belief-driven growth fluctuations. ${ }^{7}$ On the contrary, Benhabib and Farmer (1994) find that the same parameterization yields local determinacy and saddle path stability without income taxation $(\eta=1$ and $\phi=0)$. These results together imply that in sharp contrast to a conventional automatic stabilizer, progressive taxation may destabilize an endogenously growing macroeconomy by generating cyclical fluctuations driven by agents' animal spirits.

The intuition for the above indeterminacy result can be understood through the model's phase diagram illustrated in Figure 2. Using (17) and (18), we find that the equilibrium loci $\dot{h}_{t}=0$ and $\dot{z}_{t}=0$ are upward sloping, and that the $\dot{z}_{t}=0$ locus is steeper than the positivelysloped stable arm (denoted as $S S$ ), followed by $\dot{h}_{t}=0$. Next, start from a particular balanced growth path $\left(h^{*}, z^{*}\right)$, and suppose that agents become optimistic about the economy's future. Acting upon this anticipation, households will invest more and consume less today, which in turn lead to another dynamic trajectory $\left\{h_{t}^{\prime}, z_{t}^{\prime}\right\}$ that begins at $\left(h_{0}^{\prime}, z_{0}^{\prime}\right)$ with $h_{0}^{\prime}<h^{*}$ and $z_{0}^{\prime}<z^{*}$. Figure 2 shows that for this alternative path to become a self-fulfilling equilibrium,

\footnotetext{
${ }^{6}$ Notice that $k_{0}$ does not introduce an initial condition to the dynamical system (17)-(18) because the period0 values of $h_{0}$ and $c_{0}$ are both endogenously determined.

${ }^{7}$ It can be shown that anlong any balanced-growth equilibrium path, $z^{*}>\rho$ since every term on the righthand-side of equation (19) is positive. Moreover, since $0<\phi<1$ and $(1-\alpha)(1+\chi)-1-\gamma<0$, the second bracket term in the denominator of $(24)$, i.e. $[(1-\phi)(1-\alpha)(1+\chi)-1-\gamma]$, is negative.
} 
the after-tax return on investment $\left(1-\tau_{m t}\right) M P K_{t}$ must be monotonically increasing along the transitional path $S S$ as the consumption-to-capital ratio $z_{t} \equiv \frac{c_{t}}{k_{t}}$ rises. From (3)-(5) and (9)-(12), it can be shown that

$$
\operatorname{sign}\left\{\left.\frac{d\left[\left(1-\tau_{m t}\right) M P K_{t}\right]}{d z_{t}}\right|_{S S}\right\}=\operatorname{sign}\{\frac{1}{z_{t}}+\frac{1+\gamma}{h_{t}} \underbrace{\left.\frac{d h_{t}}{d z_{t}}\right|_{S S}}_{\text {positive }}\}>0 .
$$

As a consequence, agents' initial rosy expectation is validated under progressive income taxation.

\subsection{When $0<\phi<1$ and $(1-\alpha)(1+\chi)-1-\gamma>0$}

Figure 3 shows that under progressive income taxation, $f\left(z^{*}\right)$ in this formulation is an upwardsloping convex curve with a positive vertical intercept $(=\rho)$. Hence, the number of intersections between $f\left(z^{*}\right)$ and the 45-degree line in the positive quadrant can be zero, one, or two. We proceed with first deriving the critical level of tax progressivity, denoted as $\hat{\phi}$, at which $f\left(z^{*}\right)$ is tangent to the 45-degree line such that there exists a unique BGP characterized by $\hat{z}$ and thus the equilibrium growth rate $\theta(\hat{z})$. Using $(22)$ with $f^{\prime}(\hat{z})=1$ and (19) evaluated at $\hat{z}$, it is straightforward to show that

$$
\hat{z}=\frac{\rho(1-\alpha)(1+\chi)}{1+\gamma}
$$

and that $\hat{\phi} \in(0,1)$ is the unique solution to the following equation: ${ }^{8}$

$$
\frac{\rho[(1-\alpha)(1+\chi)-1-\gamma]}{\eta(1+\gamma)[1-\alpha(1-\hat{\phi})]}=\left[\frac{A \rho(1+\chi)}{\eta(1-\hat{\phi})(1+\gamma)}\right]^{\frac{(1-\alpha)(1+\chi)}{(1-\alpha)(1+\chi)-1-\gamma}} .
$$

Next, we find that an increase in the tax progressivity $\phi$ shifts the locus of $f\left(z^{*}\right)$ upwards because

$$
\frac{\partial f\left(z^{*}\right)}{\partial \phi}=\frac{\eta[(1-\alpha)(1+\chi)-\alpha(1-\phi)(1+\gamma)]}{(1-\phi)[(1-\alpha)(1+\chi)-1-\gamma]}\left[\frac{A z^{*}}{\eta(1-\phi)(1-\alpha)}\right]^{\frac{(1-\alpha)(1+\chi)}{(1-\alpha)(1+\chi)-1-\gamma}}>0
$$

which in turn implies that our model possesses no (two) balanced growth path(s) provided $\phi>(<) \hat{\phi}^{9}$ Hence, any small deviation from the balanced growth path with $\hat{z}$ and $\theta(\hat{z})$

\footnotetext{
${ }^{8}$ Notice that the left-hand-side of $(28)$ is decreasing with respect to $\hat{\phi}$, whereas the right-hand-side is monotonically increasing. It follows that there will be a unique intersection that determines $\hat{\phi}$.

${ }^{9}$ Since $0<\alpha<1$, the bracket term in the numerator of $(29)$ is greater than $(1-\alpha)(1+\chi)-(1-\phi)(1+\gamma)$, which can be rewritten as $(1-\alpha)(1+\chi)-1-\gamma+\phi(1+\gamma)>0$.
} 
will lead to the BGP's disappearance, or the emergence of dual BGP equilibria. This result indicates that the economy undergoes a saddle-node bifurcation which may cause the hard loss of equilibrium stability, i.e. a radical qualitative change in the behavior of the dynamical system (17)-(18) takes place, as the tax-slope parameter passes through the threshold value $\hat{\phi}$.

Figure 3 also shows that when the tax progressivity $\phi<\hat{\phi}$, there exist two interior balancedgrowth equilibrium paths in our model characterized by $z_{1}^{*}$ and $z_{2}^{*}$, where $z_{1}^{*}<\hat{z}<z_{2}^{*}$. Given $(1-\alpha)(1+\chi)-1-\gamma>0$ within this specification, an increase in the consumption-to-capital ratio leads to a higher level of hours worked (see equation 20). This in turn raise the marginal product of capital and the equilibrium growth rate (see equation 21), thereby $\theta\left(z_{1}^{*}\right)<\theta(\hat{z})<$ $\theta\left(z_{2}^{*}\right)$. To help understand the resulting local stability properties, we substitute (3) into the logarithmic version of the labor-market equilibrium condition (12), and find that the slope of the after-tax equilibrium wage-hours locus is given by $(1-\phi)(1-\alpha)(1+\chi)-1$, while the slope of the household's labor supply curve is $\gamma(\geq 0)$. It turns out that the relative steepness of these two curves in the labor market plays an important role in affecting the local dynamics around both balanced-growth equilibria.

\subsubsection{When $0<\phi<\hat{\phi}<1$ and $(1-\phi)(1-\alpha)(1+\chi)-1<\gamma$}

In this case, the tax progressivity is lower than $\hat{\phi}$ such that the model economy exhibits two interior balanced-growth equilibrium paths; and higher than the critical level $\phi^{c} \equiv 1-$ $\frac{1+\gamma}{(1-\alpha)(1+\chi)}$ such that the after-tax equilibrium wage-hours locus is flatter than the labor supply curve. As a result, $0<\phi^{c}<\phi<\hat{\phi}<1$ within this specification. Using (24), it is immediately clear that the two eigenvalues of the model's Jacobian matrix $J$ are of opposite signs $($ Det $<0)$. Therefore, both BGP's are locally indeterminate that may lead to macroeconomic instability, which in turn implies that progressive income taxation operates like an automatic destabilizer raising the magnitude of business cycle fluctuations. We also find that the intuition for this indeterminacy result is identical to that in section 3.1, demonstrated by the phase diagram in Figure 2, when our model economy possesses a unique balanced-growth equilibrium. Moreover, this finding turns out to be exactly opposite to that obtained in Guo and Lansing (1998, p. $488)$ - a progressive tax policy (9) which satisfies the condition $(1-\phi)(1-\alpha)(1+\chi)-1<$ $\gamma$ will eliminate sunspot-driven fluctuations in the no-sustained-growth version of Benhabib and Farmer's (1994) economy with an indeterminate steady state under sufficiently strong increasing returns-to-scale in aggregate production. 
3.2.2 When $0<\phi<\hat{\phi}<1$ and $(1-\phi)(1-\alpha)(1+\chi)-1>\gamma$

In this case, $0<\phi<\phi^{c}<\hat{\phi}<1$ thus (i) there exists two interior BGP equilibria in the economy, and (ii) the after-tax equilibrium wage-hours locus is positively-sloped and steeper than the labor supply curve. Since $0<\alpha, \phi<1$ and $\gamma \geq 0$, together with $z_{2}^{*}>z_{1}^{*}>\rho>0$ (see footnote 7$)$ and $(1-\phi)(1-\alpha)(1+\chi)-1>\gamma$, the Jacobian matrix $J$ for this configuration possesses a positive determinant $($ Det $>0)$. Using (25), (27) and $z_{1}^{*}<\hat{z}<z_{2}^{*}$ as seen in Figure 3, it is straightforward to show that $\operatorname{Tr}\left(z_{2}^{*}\right)<\operatorname{Tr}(\hat{z})<\operatorname{Tr}\left(z_{1}^{*}\right)$, where $\operatorname{Tr}(\hat{z})$ denotes the Jacobian's trace evaluated at $z^{*}=\hat{z}$ given by

$$
\operatorname{Tr}(\hat{z})=\frac{\rho \phi[\alpha(1-\phi)(1-\alpha)(1+\chi)-1-\gamma]}{[1-\alpha(1-\phi)][(1-\phi)(1-\alpha)(1+\chi)-1-\gamma]} \gtrless 0 .
$$

Without being able to obtain the analytical expressions of $z_{1}^{*}$ and $z_{2}^{*}$ from solving equation (19), we can not derive the exact condition that governs the local stability properties for this version of our model. As a result, numerical experiments are conducted to quantitatively explore the economy's equilibrium dynamics. Per the parameterization that is commonly adopted in the RBC-based indeterminacy literature, the capital share of national income, $\alpha$, is chosen to be $\frac{1}{3}$; the time discount rate, $\rho$, is set equal to 0.01 ; the capital depreciation rate, $\delta$, is fixed at 0.025 ; the household's labor supply elasticity, $\gamma$, is calibrated to be 0 (i.e. indivisible labor); and the preference parameter, $A$, is normalized to 1 . In addition, we set the degree of productive externalities from hours worked $\chi=0.6,{ }^{10}$ and the tax-level parameter $\eta=0.8$ based on the average value of Chen and Guo's (2013) year-by-year point estimates from the 1966-2005 U.S. federal individual income tax schedule.

Given these baseline parameter values, we find that $\phi^{c}=0.0625$ and $\hat{\phi}=0.9689$; and that the requisite condition $(1-\phi)(1-\alpha)(1+\chi)-1>\gamma$ is satisfied for all positive values of the tax progressivity $\phi<\phi^{c}$. Next, since the bracket term in the numerator of (30), $\alpha(1-\phi)(1-\alpha)(1+\chi)-1-\gamma$, is now smaller than zero, $\operatorname{Tr}(\hat{z})$ and thus $\operatorname{Tr}\left(z_{2}^{*}\right)$ both will be negative. This implies that in the neighborhood of the BGP associated with $z_{2}^{*}$ and $\theta\left(z_{2}^{*}\right)$, the model's Jacobian matrix $J$ possesses a negative trace and a positive determinant. Therefore, the high-growth equilibrium path is a sink that exhibits indeterminacy and sunspots. On the other hand, we numerically verify that $\operatorname{Tr}\left(z_{1}^{*}\right)>0$ under the benchmark parameteriza-

\footnotetext{
${ }^{10}$ Given $\alpha=\frac{1}{3}$ and $\gamma=0$, the minimum level of labor externalities in firms' production that satisfies the condition needed for the possibility of multiple interior BGP's, $(1-\alpha)(1+\chi)-1-\gamma>0$, is $\chi_{\min }=0.51$. The (in)stability results reported in this subsection remain qualitatively unchanged over the range of $\chi \in[0.51,0.8]$, where $\chi=0.8$ leading to $(1-\alpha)(1+\chi)=1.2$ is considered by Benhabib and Farmer $(1994$, p. 38) in their quantitative analysis.
} 
tion, hence the low-growth BGP associated with $z_{1}^{*}$ and $\theta\left(z_{1}^{*}\right)$ displays saddle-path stability and equilibrium uniqueness in that both eigenvalues have positive real parts. In this case, progressive income taxation does not affect equilibrium (in)determinacy as the two interior balanced-growth equilibria in Benhabib and Farmer's (1994) laissez-faire economy also exhibit exactly the same local stability properties.

Figure 4 presents the phase diagram for the indeterminate high-growth BGP characterized by $z_{2}^{*}$ and $\theta\left(z_{2}^{*}\right)$. As in Figure 2, the positively-sloped $\dot{h}_{t}=0$ locus is flatter than $\dot{z}_{t}=0$; however, the associated upward-sloping stable arms, denoted as $S S_{1}$ and $S S_{2}$ with each corresponding to a negative real eigenvalue, ${ }^{11}$ are the flattest. When the representative household deviates from the original balanced-growth equilibrium $\left(h^{*}, z^{*}\right)$ and lowers today's consumption because of its optimism about the economy's future, the resulting dynamic trajectory $\left\{h_{t}^{\prime}, z_{t}^{\prime}\right\}$ will begin at $\left(h_{0}^{\prime}, z_{0}^{\prime}\right)$ with $h_{0}^{\prime}<h^{*}$ and $z_{0}^{\prime}<z^{*}$. Figure 4 shows that when $z_{t} \equiv \frac{c_{t}}{k_{t}}$ increases monotonically along a convergent transitional path, the equilibrium after-tax marginal product of capital $\left(1-\tau_{m t}\right) M P K_{t}$ must be rising in order to justify $\left\{z_{t}^{\prime}, x_{t}^{\prime}\right\}$ as a self-fulfilling equilibrium path. Using (26), we find that this requisite condition is satisfied, i.e. $\frac{d\left[\left(1-\tau_{m t}\right) M P K_{t}\right]}{d z_{t}}>0$, along either $S S_{1}$ or $S S_{2}$, hence agents' initial optimistic expectations are validated.

\subsection{When $\phi=0$}

In this case, the tax schedule (9) becomes flat with $\tau_{t}=\tau_{m t}=1-\eta$ for all $t$. Resolving our model with $\phi=0$ yields the following single differential equation in $z_{t} \equiv \frac{c_{t}}{k_{t}}$ that describes its equilibrium dynamics:

$$
\frac{\dot{z}_{t}}{z_{t}}=\eta(\alpha-1)\left[\frac{A z_{t}}{\eta(1-\alpha)}\right]^{\frac{(1-\alpha)(1+\chi)}{(1-\alpha)(1+\chi)-1-\gamma}}+z_{t}-\rho .
$$

Following the same procedure as in section 2.4, an interior balanced-growth equilibrium is characterized by a positive real number $z^{*}$ that satisfies $\dot{z}_{t}=0$, which leads to

$$
z^{*}=\rho+\eta(1-\alpha)\left[\frac{A z^{*}}{\eta(1-\alpha)}\right]^{\frac{(1-\alpha)(1+\chi)}{(1-\alpha)(1+\chi)-1-\gamma}} \equiv g\left(z^{*}\right)
$$

where

\footnotetext{
${ }^{11}$ Given the baseline parameterization mentioned above, the two eigenvalues associated with the high-growth BGP are found to be real and negative. This result continues to hold when $\chi$ takes alternative values from the interval $[0.51,0.8]$.
} 
$g^{\prime}\left(z^{*}\right)=\frac{\eta(1-\alpha)^{2}(1+\chi)}{[(1-\alpha)(1+\chi)-1-\gamma] z^{*}}\left[\frac{A z^{*}}{\eta(1-\alpha)}\right]^{\frac{(1-\alpha)(1+\chi)}{(1-\alpha)(1+\chi)-1-\gamma}} \lessgtr 0$ when $(1-\alpha)(1+\chi)-1-\gamma \lessgtr 0$,

and

$$
g^{\prime \prime}\left(z^{*}\right)=\frac{(1+\gamma) g^{\prime}\left(z^{*}\right)}{[(1-\alpha)(1+\chi)-1-\gamma] z^{*}}>0
$$

We then linearize (31) around $z^{*}$ and find that the model's equilibrium dynamics are deter-

mined by the eigenvalue $\left[1-g^{\prime}\left(z^{*}\right)\right] z^{*}$. Similar to Figure $1, g\left(z^{*}\right)$ is a downward-sloping and convex curve when $(1-\alpha)(1+\chi)-1-\gamma<0$, hence the economy possesses a unique balancedgrowth equilibrium that turns out to a saddle path because the associated eigenvalue is positive and there is no given initial condition in equation (31). When $(1-\alpha)(1+\chi)-1-\gamma>0$, it is straightforward to show the existence of two interior BGP equilibria (similar to Figure 3) with $z_{1}^{*}<z_{2}^{*}, 0<g^{\prime}\left(z_{1}^{*}\right)<1$ and $g^{\prime}\left(z_{2}^{*}\right)>1$. As a result, the high-growth equilibrium is a sink in that $\left[1-g^{\prime}\left(z_{2}^{*}\right)\right] z_{2}^{*}<0$, whereas the low-growth equilibrium is a saddle due to $\left[1-g^{\prime}\left(z_{1}^{*}\right)\right] z_{1}^{*}>0$. These findings illustrate that our endogenously growing macroeconomy under flat income taxation exhibits the same local stability properties as those in Benhabib and Farmer's (1994) otherwise identical model under laissez faire.

\section{Linearly Progressive Taxation}

Dromel and Pintus (2007) point out that the feature of continuously increasing average and marginal tax rates a la equations (9)-(10) is not consistent with the progressive tax policies observed in many developed countries, hence they incorporate an alternative fiscal formulation into Benhabib and Farmer's (1994) indeterminate one-sector real business cycle model under laissez faire and no endogenous growth. Specifically, a constant marginal tax rate is imposed on the household's taxable income when it exceeds a fixed exemption threshold, namely linearly progressive taxation is levied. As in Guo and Lansing (1998), these authors find that the economy will be immune to sunspot-driven cyclical fluctuations when the exemption threshold is larger than a critical level, or when the associated tax progressivity is sufficiently high.

In this section, we adopt the time-varying version of Dromel and Pintus' (2007) linearly progressive tax formulation and then examine its (de)stabilization effects within the endogenously growing macroeconomy described in section 2 . The budget constraint faced by the representative household is now changed to 


$$
c_{t}+\dot{k}_{t}+\delta k_{t}=y_{t}-\underbrace{\tau\left(y_{t}-E_{t}\right)}_{\text {Tax Paid }}, \quad E_{0} \geq 0 \text { given, }
$$

where $y_{t}\left(=r_{t} k_{t}+w_{t} h_{t}\right)$ is the household's taxable income, and $E_{t}$ represents the exemption threshold that is postulated to grow continuously at the same rate as per-capita output on the economy's balanced growth path, i.e. $\frac{\dot{E}_{t}}{E_{t}}=\frac{\dot{y}_{t}^{*}}{y_{t}^{*}}=\theta$ for all $t$. As in Dromel and Pintus (2007), we first analyze the environment with $y_{t}>E_{t}>0$ for all $t$, and a constant marginal tax rate $\tau \in(0,1)$ that is higher than the corresponding average tax rate given by $\tau\left(1-\frac{E_{t}}{y_{t}}\right)$. It follows that the tax schedule under consideration here is progressive.

Next, it is straightforward to show that (i) the equilibrium conditions for this specification can be represented by the following autonomous dynamical system in terms of $x_{t} \equiv \frac{E_{t}}{y_{t}}$ and $z_{t} \equiv \frac{c_{t}}{k_{t}}$ with no given initial condition:

$$
\begin{aligned}
& \frac{\dot{x}_{t}}{x_{t}}=\theta+\rho+\delta-\alpha(1-\tau)\left[\frac{A z_{t}}{(1-\tau)(1-\alpha)}\right]^{\frac{(1-\alpha)(1+\chi)}{(1-\alpha)(1+\chi)-1-\gamma}}-\frac{1+\gamma}{(1-\alpha)(1+\chi)-1-\gamma} \frac{\dot{z}_{t}}{z_{t}} \\
& \frac{\dot{z}_{t}}{z_{t}}=z_{t}-\rho-\left[(1-\tau)(1-\alpha)+\tau x_{t}\right]\left[\frac{A z_{t}}{(1-\tau)(1-\alpha)}\right]^{\frac{(1-\alpha)(1+\chi)}{(1-\alpha)(1+\chi)-1-\gamma}}
\end{aligned}
$$

(ii) the existence and number of the economy's interior balanced growth path(s) are governed by

$$
z^{*}=\rho+\frac{\tau E_{0}}{k_{0}}+(1-\tau)(1-\alpha)\left[\frac{A z^{*}}{(1-\tau)(1-\alpha)}\right]^{\frac{(1-\alpha)(1+\chi)}{(1-\alpha)(1+\chi)-1-\gamma}} \equiv m\left(z^{*}\right)
$$

where

$$
m^{\prime}\left(z^{*}\right)=\frac{(1-\tau)(1-\alpha)^{2}(1+\chi)}{[(1-\alpha)(1+\chi)-1-\gamma] z^{*}}\left[\frac{A z^{*}}{(1-\tau)(1-\alpha)}\right]^{\frac{(1-\alpha)(1+\chi)}{(1-\alpha)(1+\chi)-1-\gamma}} \lessgtr 0 \text { when }(1-\alpha)(1+\chi)-1-\gamma \lessgtr 0
$$

and

$$
m^{\prime \prime}\left(z^{*}\right)=\frac{(1+\gamma) m^{\prime}\left(z^{*}\right)}{[(1-\alpha)(1+\chi)-1-\gamma] z^{*}}>0
$$

and (iii) the determinant and trace of the resulting Jacobian matrix are 


$$
\begin{aligned}
\text { Det } & =-\frac{\tau(1-\alpha)(1+\chi) x^{*}}{\alpha(1-\tau)[(1-\alpha)(1+\chi)-1-\gamma]}\left[\frac{\alpha(1-\tau)\left(z^{*}-\rho\right)}{(1-\tau)(1-\alpha)+\tau x^{*}}\right]^{2}, \\
\operatorname{Tr} & =\rho-\frac{(1-\tau)(1-\alpha)(1+\gamma)}{(1-\alpha)(1+\chi)-1-\gamma}\left[\frac{A z^{*}}{(1-\tau)(1-\alpha)}\right]^{\frac{(1-\alpha)(1+\chi)}{(1-\alpha)(1+\chi)-1-\gamma}} .
\end{aligned}
$$

Interestingly, the requisite condition that governs the number of balanced growth path(s) in this setting turns out to be identical to that in section 3 under Guo and Lansing's (1998) nonlinear fiscal policy rule. When $(1-\alpha)(1+\chi)-1-\gamma<0$, there exists a unique balancedgrowth equilibrium path in that $m\left(z^{*}\right)$ is a negatively-sloped and convex curve (similar to Figure 1). Given $z^{*}>\rho>0$ (see equation 38), the BGP expressions of all other endogenous variables can be easily derived. ${ }^{12}$ We also find that the Jacobian's determinant (41) and trace (42) for this configuration are positive, hence both eigenvalues have positive real parts. It follows that as in Benhabib and Farmer's (1994) laissez-faire counterpart, the economy's unique balanced-growth equilibrium under linearly progressive taxation continues to display saddle path stability without the possibility of endogenous cyclical fluctuations.

On the other hand, Figure 5 depicts that the number of balanced growth paths can be zero, one, or two when $(1-\alpha)(1+\chi)-1-\gamma>0$. As in section 3.2 , we use $(39)$ with $m^{\prime}(\hat{z})=1$ and (38) evaluated at $\hat{z}$ to obtain

$$
\hat{z}=\frac{(1-\alpha)(1+\chi)}{1+\gamma}\left(\rho+\frac{\tau \hat{E}}{k_{0}}\right)
$$

where $\hat{E}$ is the unique solution to the following equation: ${ }^{13}$

$\rho+\frac{\tau \hat{E}}{k_{0}}=\frac{(1-\tau)(1-\alpha)(1+\gamma)}{(1-\alpha)(1+\chi)-1-\gamma}\left[\frac{A(1+\chi)}{(1-\tau)(1+\gamma)}\left(\rho+\frac{\tau \hat{E}}{k_{0}}\right)\right]^{\frac{(1-\alpha)(1+\chi)}{(1-\alpha)(1+\chi)-1-\gamma}} \equiv \Psi\left(\rho+\frac{\tau \hat{E}}{k_{0}}\right)$.

Figure 5 also shows that an increase in $E_{0}$ shifts the locus of $m\left(z^{*}\right)$ upwards because of a higher vertical intercept, thus two balanced-growth equilibria characterized by $z_{1}^{*}<\hat{z}<z_{2}^{*}$

\footnotetext{
${ }^{12}$ It can be shown that along the economy's balanced growth path, $h^{*}=\left[\frac{A z^{*}}{(1-\tau)(1-\alpha)}\right]^{\frac{1}{(1-\alpha)(1+\chi)-1-\gamma}}, x^{*}=$ $\frac{E_{0}}{k_{0}\left(h^{*}\right)^{(1-\alpha)(1+\chi)}}$ and $\theta=\alpha(1-\tau)\left(h^{*}\right)^{(1-\alpha)(1+\chi)}-\delta-\rho$.

${ }^{13}$ It is straightforward to show that the plot of $\Psi(\cdot)$ on the right-hand-side of (44) is an upward-sloping and convex curve that begins at the origin. As a result, this locus will intersect the 45-degree line once in the positive quadrant, which in turn determines the unique $\hat{E}$.
} 
will emerge when $E_{0}<\hat{E}$. In this case, the model's Jacobian matrix possesses a negative determinant a la (41), indicating that the two eigenvalues are of opposite signs. Therefore, both BGP's exhibit equilibrium indeterminacy and belief-driven growth fluctuations, which in turn implies that linearly progressive taxation may also operate like an automatic destabilizer in our endogenously growing macroeconomy. Intuitively, when households become optimistic and decide to raise their investment expenditures today, it can be shown that the aforementioned mechanism that makes for multiple equilibria, i.e. an increase in the equilibrium after-tax marginal product of capital, will generate convergent trajectories toward the original balanced growth path. As a result, agents' initial rosy anticipation about the economy's future is validated.

Finally, when the tax schedule is flat with $E_{t}=0$ for all $t$, we find that the model's equilibrium conditions are described by the following single differential equation in $z_{t} \equiv \frac{c_{t}}{k_{t}}$ :

$$
\frac{\dot{z}_{t}}{z_{t}}=[(1-\tau)(\alpha-1)-\tau]\left[\frac{A z_{t}}{(1-\tau)(1-\alpha)}\right]^{\frac{(1-\alpha)(1+\chi)}{(1-\alpha)(1+\chi)-1-\gamma}}+z_{t}-\rho .
$$

Since the right-hand-side of (45) only differs from that of (31) with the constant term in front

of $z_{t}^{\frac{(1-\alpha)(1+\chi)}{(1-\alpha)(1+\chi)-1-\gamma}}$, they will yield identical local dynamics after the linearization around their respective balanced growth path(s). It follows that as in section 3.3, our endogenously growing economy under the Dromel-Pintus formulation of flat income taxation display the same macroeconomic (in)stability properties as those in Benhabib and Farmer's (1994) otherwise identical model under laissez faire.

In sum, the preceding analyses have shown that the conventional view about progressive income taxation, as well as the findings of Guo and Lansing (1998) and Dromel and Pintus (2007), can be reversed in a one-sector representative agent model that exhibits sustained endogenous growth. Table 1 summarizes our results on the interrelations between income taxation and equilibrium (in)determinacy, together with those obtained in Benhabib and Farmer (1994) without government intervention and persistent growth as a reference point, in each parametric specification that has been examined.

\section{Conclusion}

This paper systematically examines the interrelations between progressive taxation of income and macroeconomic (in)stability in a one-sector model of endogenous growth with variable labor supply and useless public spending. In stark contrast to traditional Keynesian-type 
stabilization policies, we find that progressive taxation may operate like an automatic destabilizer which yields equilibrium indeterminacy and belief-driven fluctuations within several parametric specifications of our endogenously growing macroeconomy. Under Guo and Lansing's (1998) continuously progressive tax schedule, this instability result is obtained when the model exhibits (i) a unique balanced-growth equilibrium, or (ii) dual BGP equilibria and the after-tax equilibrium wage-hours locus is flatter than the labor supply curve. Under Dromel and Pintus's (2007) linearly progressive tax scheme, indeterminacy and sunspots will arise when the model possesses two balanced growth paths. Not only these findings make valuable theoretical contributions to the academic literature, they also provide important implications about the (de)stabilization role of tax policies in a macroeconomy with sustained endogenous growth.

This paper can be extended in several directions. For example, it would be worthwhile to explore alternative mechanisms for generating endogenous growth (e.g. human capital accumulation), and/or an economy with national debt or multiple production sectors. In addition, we can incorporate features that are commonly adopted in the new-Keynesian literature, such as price stickiness, wage rigidity and investment adjustment costs, among others. These possible extensions will allow us to examine the robustness of this paper's theoretical results and policy implications, as well as further enhance our understanding of the relationship between progressive taxation and macroeconomic (in)stability in an endogenously growing economy. We plan to pursue these research projects in the near future. 


\section{References}

[1] Baier, S.L. and G. Glomm (2001), "Long-Run Growth and Welfare Effects of Public Policies with Distortionary Taxation," Journal of Economic Dynamics and Control 25, 2007-2042.

[2] Barro, R.J. (1990), "Government Spending in a Simple Model of Endogenous Growth," Journal of Political Economy 98, S103-S125.

[3] Barro, R.J. and X. Sala-i-Martin (1992), "Public Finances in Models of Economic Growth," Review of Economic Studies 59, 645-661.

[4] Benhabib, J. and R.E.A. Farmer (1994), "Indeterminacy and Increasing Returns," Journal of Economic Theory 63, 19-41.

[5] Cazzavillan, G. (1996), "Public Spending, Endogenous Growth, and Endogenous Fluctuations," Journal of Economic Theory 71, 394-415.

[6] Chen, B.-L. (2006), "Public Capital, Endogenous Growth, and Endogenous Fluctuations," Journal of Macroeconomics 28, 768-774.

[7] Chen, S.-H. and J.-T. Guo (2013), "On Indeterminacy and Growth under Progressive Taxation and Productive Government Spending," Canadian Journal of Economics 46, 865-880.

[8] Chen, S.-H. and J.-T. Guo (2015), "Progressive Taxation, Endogenous Growth, and Macroeconomic (In)stability" unpublished manuscript.

[9] Dromel, N.L. and P.A. Pintus (2007), "Linearly Progressive Income Taxes and Stabilization," Reserach in Economics 61, 25-29.

[10] Futagami, K., Y. Morita and A. Shibata (1993), "Dynamic Analysis of an Endogenous Growth Model with Public Capital," Scandinavian Journal of Economics 95, 607-625.

[11] Greiner, A. (2006), "Progressive Taxation, Public Capital, and Endogenous Growth," FinazArchiv 62, 353-366.

[12] Greiner, A. (2007), "An Endogenous Growth Model with Public Capital and Sustainable Government Debt," Japanese Economic Review 58, 345-361.

[13] Glomm G. and B. Ravikumar (1994), "Public Investment in Infrastructure in a Simple Growth Model," Journal of Economic Dynamics and Control 18, 1173-1187.

[14] Glomm G. and B. Ravikumar (1997), "Productive Government Expenditures and LongRun Growth," Journal of Economic Dynamics and Control 21, 183-204.

[15] Guo, J.-T. and K.J. Lansing (1998), "Indeterminacy and Stabilization Policy," Journal of Economic Theory 82, 481-490.

[16] Hu, Y., R. Ohdoi and K. Shimomura (2008), "Indeterminacy in a Two-Sector Endogenous Growth Model with Productive Government Spending," Journal of Macroeconomics 30, 1104-1123.

[17] Li, W. and P-D. Sarte (2004), "Progressive Taxation and Long-Run Growth," American Economic Review 94, 1705-1716.

[18] Palivos, T., C.Y. Yip and J. Zhang (2003), "Transitional Dynamics and Indeterminacy of Equilibria in an Endogenous Growth Model with a Public Input," Review of Development Economics 7, 86-98. 
[19] Park, H. and A. Philippopoulos (2002), "Dynamics of Taxes, Public Services, and Endogenous Growth," Macroeconomic Dynamics 6, 187-201.

[20] Schmitt-Grohé, S. and M. Uribe (1997), "Balanced-Budget Rules, Distortionary Taxes and Aggregate Instability," Journal of Political Economy 105, 976-1000.

[21] Slobodyan, S. (2006), "One Sector Models, Indeterminacy and Productive Public Spending," CERGE-EI Working Paper Series No. 293.

[22] Turnovsky, S.J. (1997), "Fiscal Policy in a Growing Economy with Public Capital," Macroeconomic Dynamics 1, 615-639.

[23] Turnovsky, S.J. (1999), "Productive Government Expenditures in a Stochastically Growing Economy," Macroeconomic Dynamics 3, 544-570.

[24] Yamarik, S. (2001), "Nonlinear Tax Structures and Endogenous Growth," Manchester School 69, 16-30.

[25] Zhang, J. (2000), "Public Services, Increasing Returns, and Equilibrium Dynamics," Journal of Economic Dynamics and Control 24, 227-246. 


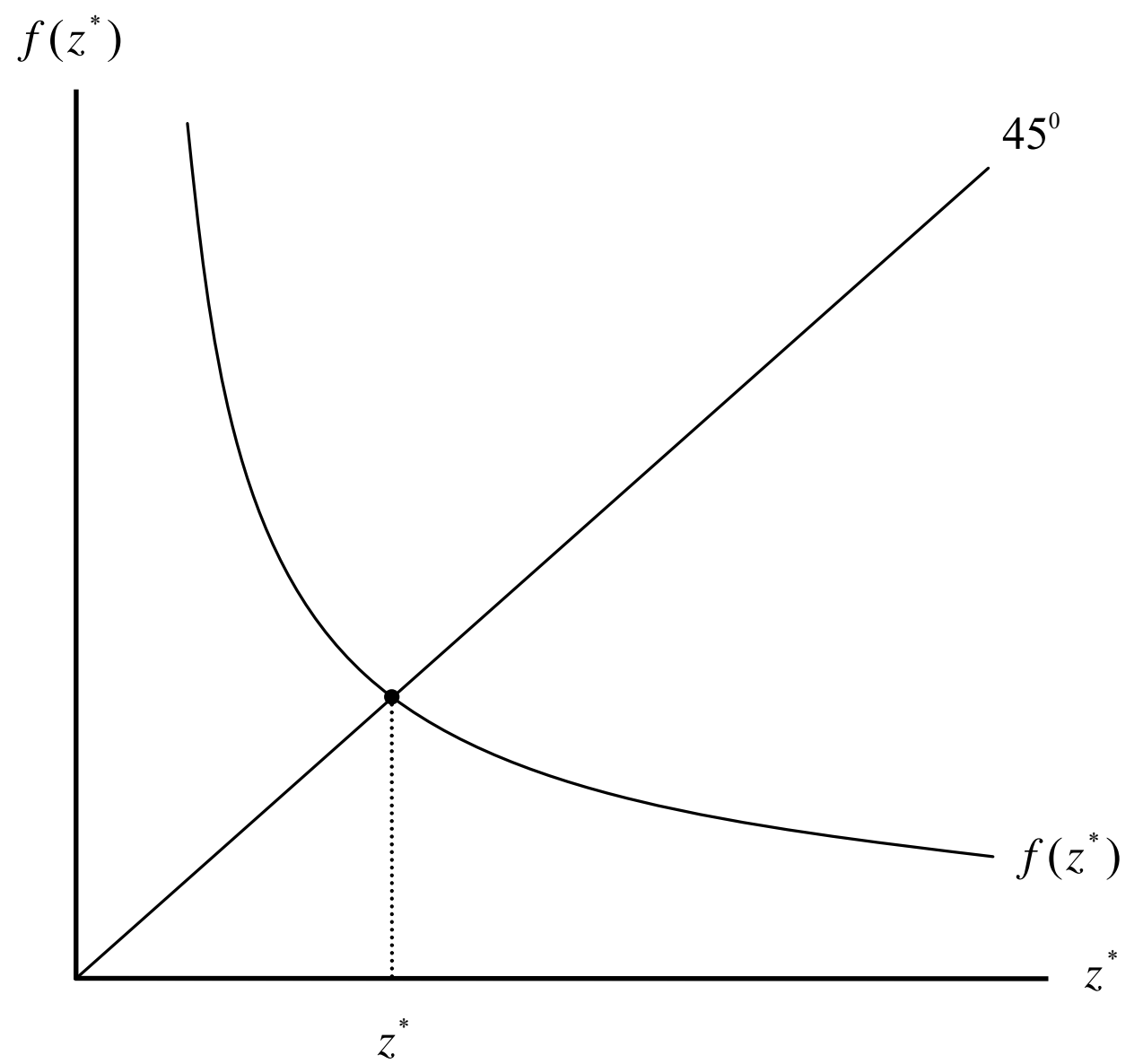

Figure 1. When $0<\phi<1$ and $(1-\alpha)(1+\chi)-1-\gamma<0$ : Unique BGP 


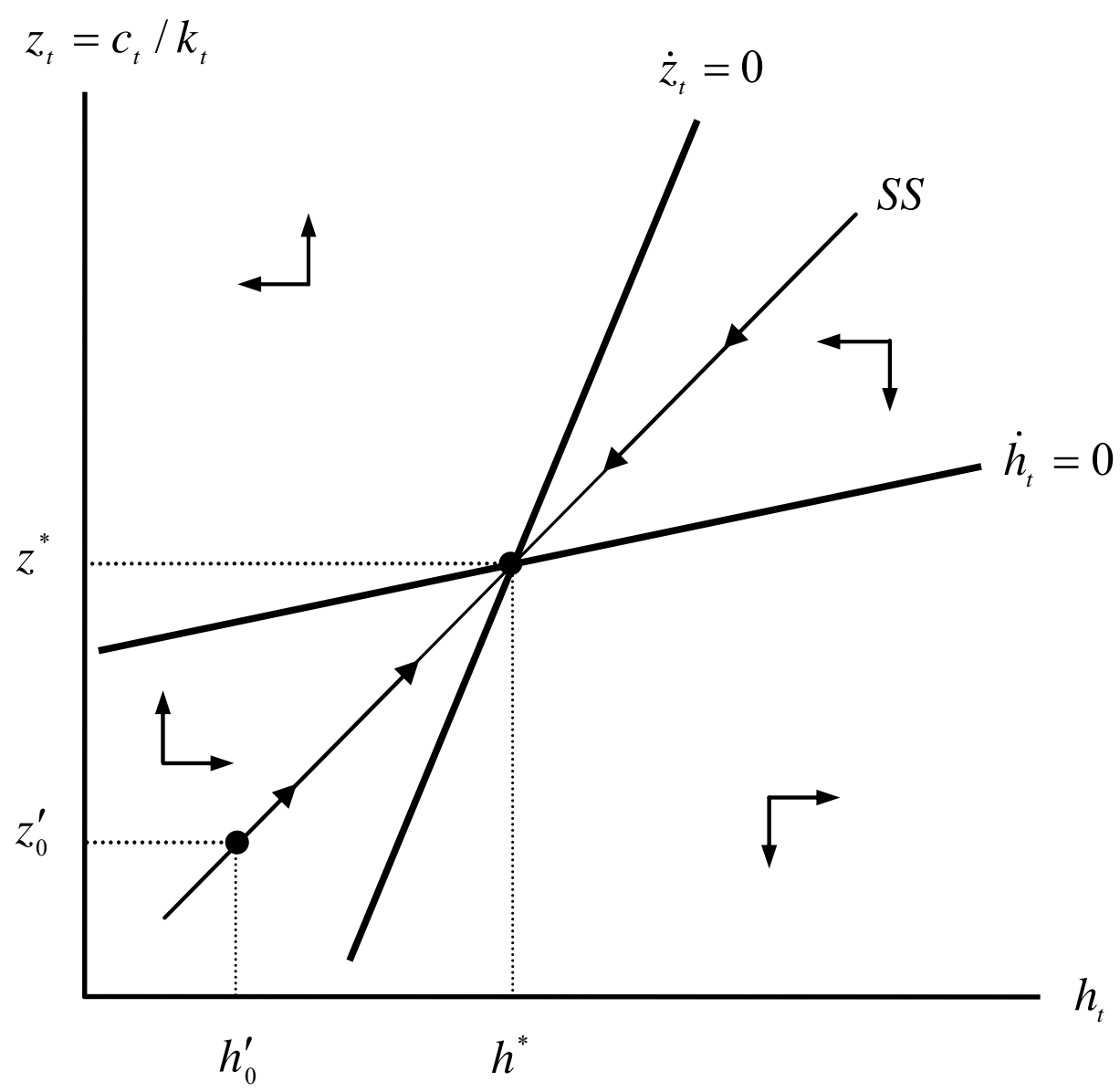

Figure 2. When $0<\phi<1$ and $(1-\alpha)(1+\chi)-1-\gamma<0$ : Indeterminacy 


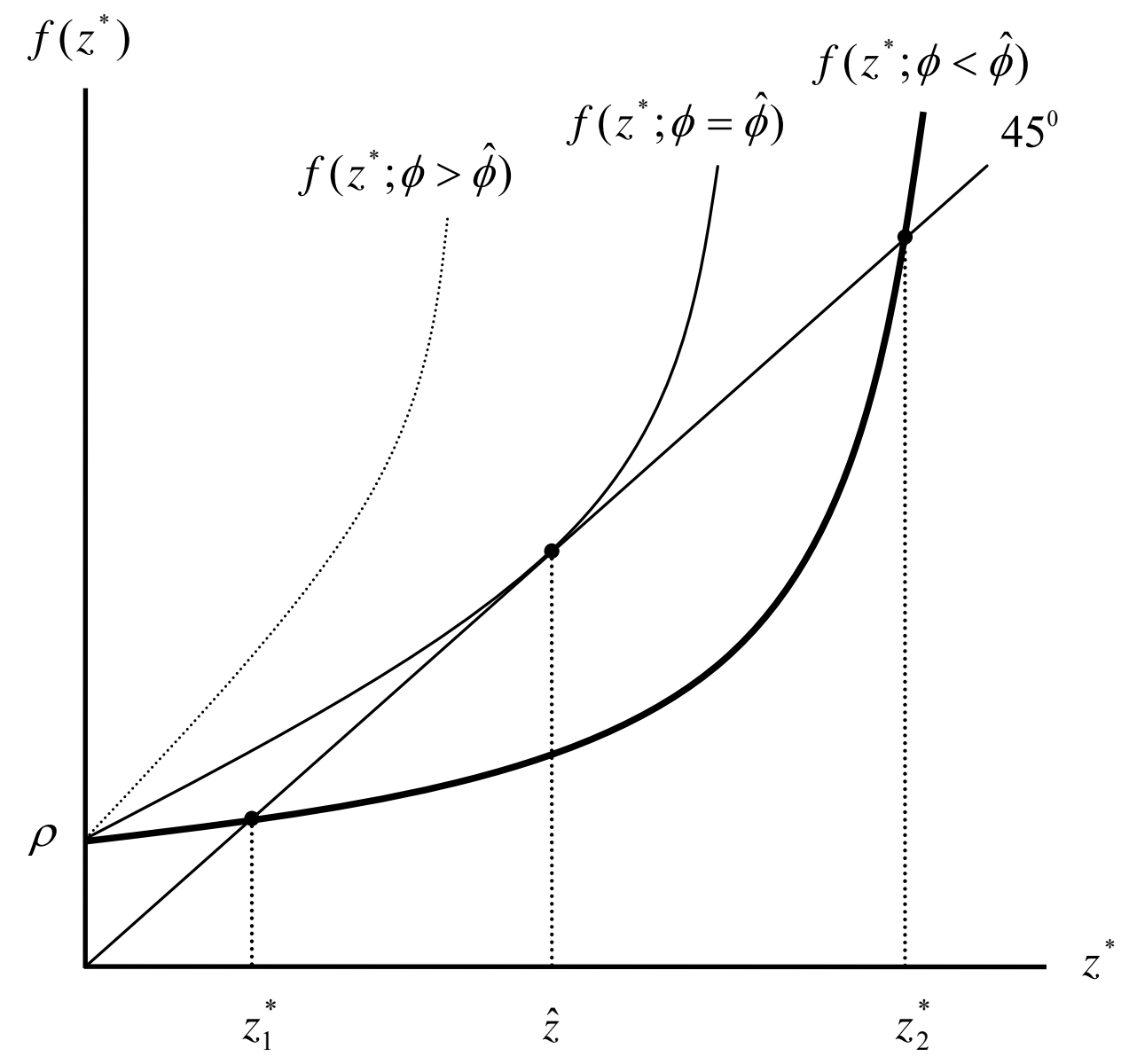

Figure 3. When $0<\phi<1$ and $(1-\alpha)(1+\chi)-1-\gamma>0$ : Possible Multiple BGP's 


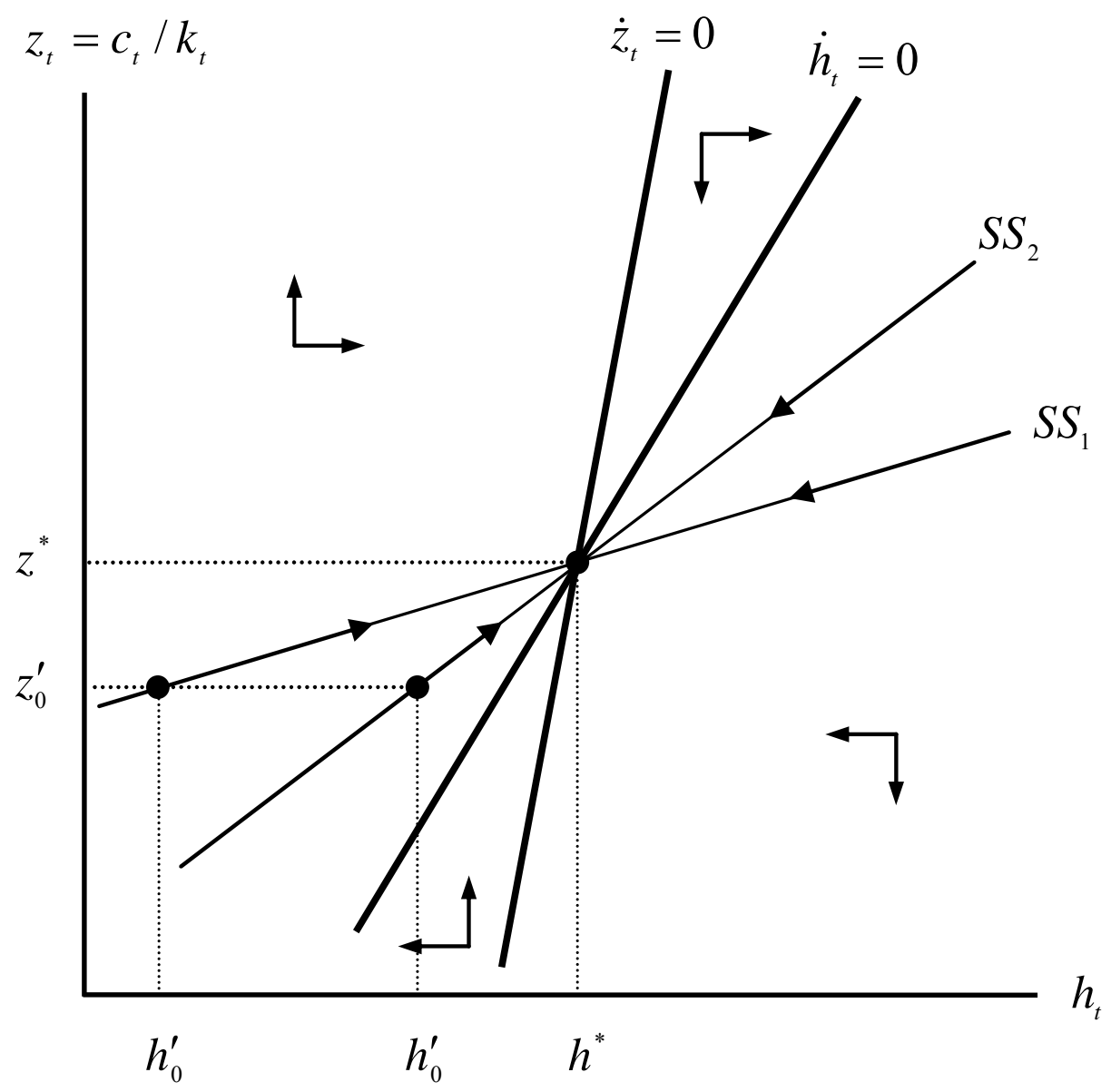

Figure 4. When $0<\hat{\phi}<\phi<1$ and $(1-\phi)(1-\alpha)(1+\chi)-1-\gamma>0$ : Indeterminacy of the High-Growth BGP 


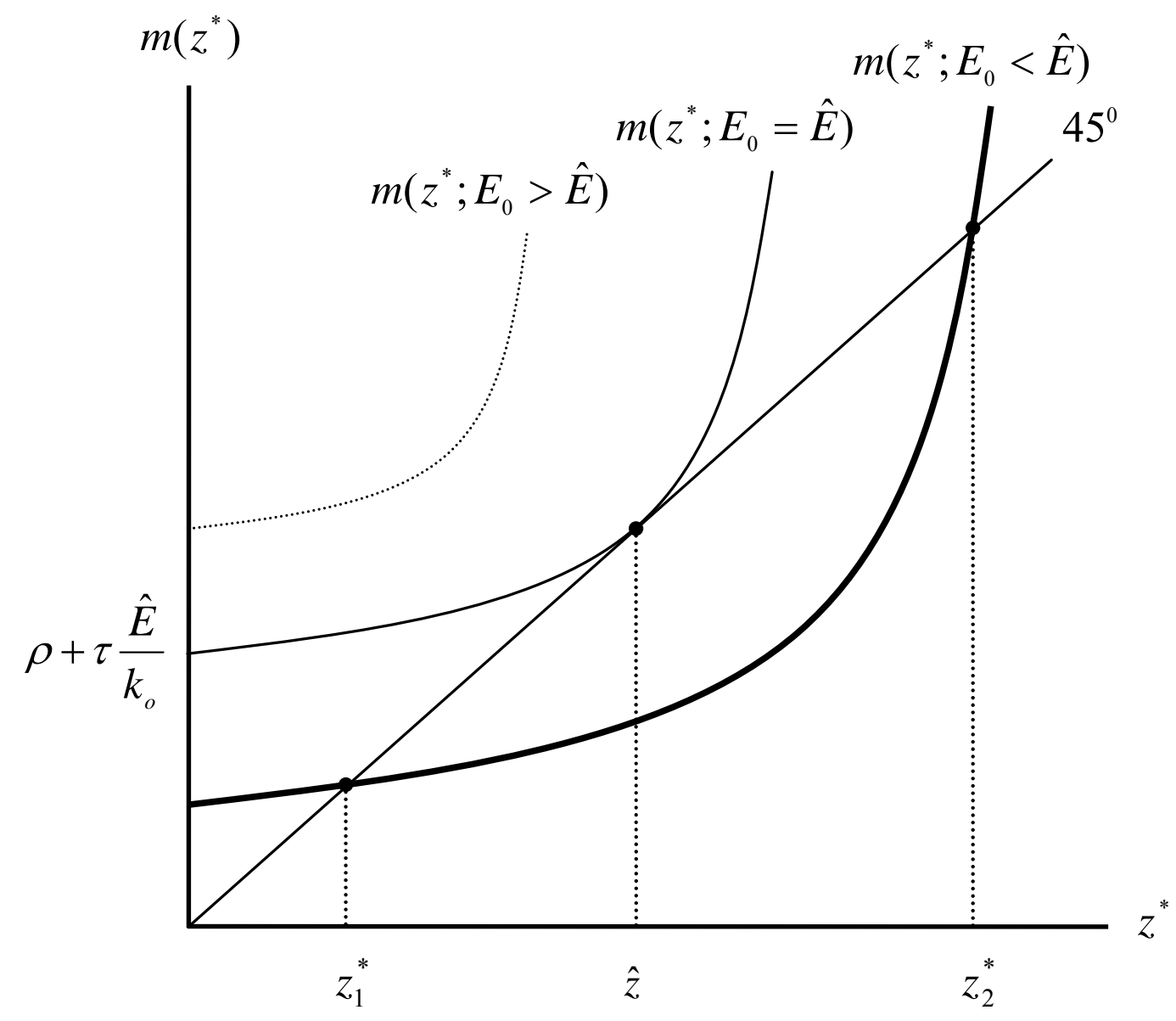

Figure 5. Linearly Progressive Tax and $(1-\alpha)(1+\chi)-1-\gamma>0$ : Possible Multiple BGP's 
Table 1. Income Taxation and Equilibrium (In)determinacy under Endogenous Growth

\begin{tabular}{|c|c|c|c|}
\hline & $\begin{array}{l}\text { Guo and Lansing (1998) } \\
\text { Continuously Progressive Tax }\end{array}$ & $\begin{array}{l}\text { Dromel Pintus (2007) } \\
\text { Linearly Progressive Tax }\end{array}$ & $\begin{array}{c}\text { Benhabib and Farmer (1994) } \\
\text { Laissez-Faire Economy }\end{array}$ \\
\hline \multicolumn{4}{|c|}{ Progressive Income Taxation } \\
\hline $\begin{array}{c}(1-\alpha)(1+\chi)-1-\gamma<0 \\
\text { Unique BGP }\end{array}$ & Sink & Saddle & Saddle \\
\hline $\begin{array}{c}(1-\alpha)(1+\chi)-1-\gamma>0 \\
\text { Dual BGP's }\end{array}$ & $\begin{array}{l}\frac{(1-\phi)(1-\alpha)(1+\chi)-1-\gamma<0}{\text { High-Growth BGP: Sink }} \\
\text { Low-Growth BGP: Sink } \\
\frac{(1-\phi)(1-\alpha)(1+\chi)-1-\gamma>0}{\text { High-Growth BGP: Sink }} \\
\text { Low-Growth BGP: Saddle }\end{array}$ & $\begin{array}{l}\text { High-Growth BGP: Sink } \\
\text { Low-Growth BGP: Sink }\end{array}$ & $\begin{array}{l}\text { High-Growth BGP: Sink } \\
\text { Low-Growth BGP: Saddle }\end{array}$ \\
\hline \multicolumn{4}{|l|}{ Flat Income Taxation } \\
\hline $\begin{array}{c}(1-\alpha)(1+\chi)-1-\gamma<0 \\
\text { Unique BGP }\end{array}$ & Saddle & Saddle & Saddle \\
\hline $\begin{array}{c}(1-\alpha)(1+\chi)-1-\gamma>0 \\
\text { Dual BGP's }\end{array}$ & $\begin{array}{l}\text { High-Growth BGP: Sink } \\
\text { Low-Growth BGP: Saddle }\end{array}$ & $\begin{array}{l}\text { High-Growth BGP: Sink } \\
\text { Low-Growth BGP: Saddle }\end{array}$ & $\begin{array}{l}\text { High-Growth BGP: Sink } \\
\text { Low-Growth BGP: Saddle }\end{array}$ \\
\hline
\end{tabular}

